\title{
Practice and Exploration in Promoting the Economic Benefits of Qingzhiwu B\&B in Hangzhou on the Basis of Data Analysis
}

\author{
Author: Chen Yiyi, Zhou Weiwei, and Yang Huansong (Corresponding author) \\ Unit: Hangzhou Normal University
}

\begin{abstract}
With the improvement of people's living standards and quickened pace of life, they tend to enjoy the rural style tourism. Rural tourism is growing fast in the new era. The building of beautiful countryside has already become a major driving force in boosting rural tourism. Located in the northen part of the scenic spot of the West Lake, Qingzhiwu was built in the Jin Dynasty. As one of the first demonstration villages for leisure tourism in Zhejiang Province, the emerging B\&B industry has brought considerable profits to Qingzhiwu.
\end{abstract}

\section{Introduction}

B\&B is a small-scale home hotel operated by individuals, and it is favored by the public for its warm, comfortable and immersion type accommodation. This industry is developing rapidly in recent years. The B\&B operation in Hangzhou received a total of 84.894 million visitors in 2019 , an increase of $23.3 \%$ year on year. By 2020 , there were 201 businesses, including 107 B\&B operations, 62 restaurants, 11 cafes and tea houses, and 21 other businesses, with B\&B accounting for 53\%[1,2]. 138 B\&B operations were located in Qingzhiwu had and 63 ones in Lanjiawan. In the travelling experience nowadays, accommodation constitutes an important link. Qingzhiwu $\mathrm{B} \& \mathrm{~B}$ belongs to a small cluster of B\&B industry. It is the first choice of many tourists to Hangzhou. Qingzhiwu $\mathrm{B} \& \mathrm{~B}$ has already become the epitome of the $\mathrm{B} \& \mathrm{~B}$ industry in China[3,4].

At present, the studies on the development of Qingzhiwu B\&B are few. This paper collected data related to Qingzhiwu B\&B from www.dianping.com and carried out analysis in a bid to provide favorable reference to the development of Qingzhiwu B\&B.

\section{Research method}

\subsection{Acquisition of data}

This paper regards the data from www.dianping.com as the basis. At the beginning of December 2020, data related to Qingzhiwu B\&B in Hangzhou on the website of www.dianping.com were collected for analysis.

\subsection{Statistical analysis}

Using Excel to turn the data into diagrams and then conducting statistical analysis. 


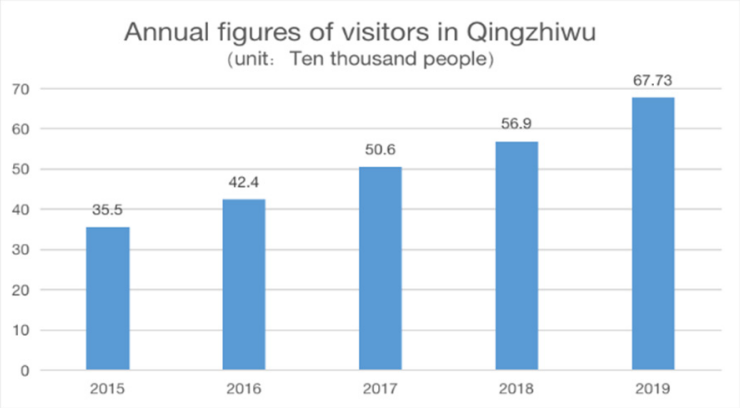

Fig 1. Annual figures of visitors in Qingzhiwu

\subsection{Percentages of online customers of Qingzhiwu B\&B}

Fig. 2 shows the analysis of B\&B customer sources based on the data obtained from the website www.dianping.com. The customers of B\&B industry and users of the platform provided by www.dianping.com are more or less the same people. The users of www.dianping.com are also potential customers of B\&B. They like sharing and very active. This website plays the role of social media, so the users can interact with each other by making comments in the comments section. With the development of the Internet, this figure will hit a new record high. Therefore, Qingzhiwu B\&B should resort to the platform of new media on the Internet for its marketing, and make full use of the multidimensional perspectives of the app of www.dianping.com to present the characteristics of B\&B.

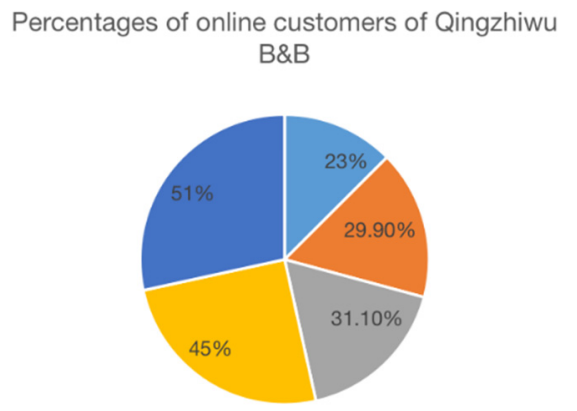

| 2015 = 2016 - 2017 = 2018 - 2019

Fig 2. Percentages of online customers of Qingzhiwu $\mathrm{B} \& \mathrm{~B}$

\subsection{The scores of 10 B\&B businesses in Qingzhiwu and per capita consumption amount}

One important reason that $\mathrm{B} \& \mathrm{~B}$ industry becomes thriving is that it has warm decorations to make the customers feel like at home. The scores of $\mathrm{B} \& \mathrm{~B}$ is important for its reputation among consumers---the higher the score is, the more likely the consumers tend to choose. Consumers, especially tourists, will value the score of $\mathrm{B} \& \mathrm{~B}$. The B\&B operators surviving in the scenic spots need to have their own characters. The people around them will offer evaluation of them. So, B\&B operators should pay close attention to the comments made by the consumers on the website of www.dianping.com since the scores would guide consumers to make decisions. The operators need to improve the management of their business according to the suggestions made by the consumers so as to provide more proper and pluralistic service.

Qingzhiwu B\&B's rating and per capita consumption

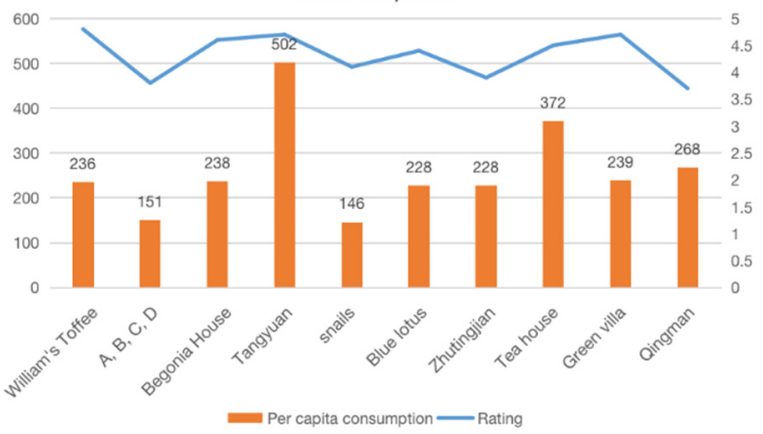

Fig 3. The scores of $10 \mathrm{~B} \& \mathrm{~B}$ businesses in Qingzhiwu and per capita consumption amount

\subsection{The types of rooms offered by Qingzhiwu $B \& B$ in Hangzhou}

Fig. 4 shows the statistical analysis based on the three types of rooms recommended by 10 Qingzhiwu B\&Bs on the website of www.dianping.com.

From Fig. 4, we can see that the types of rooms booked by the tourists coming to Qingzhiwu are concentrated. That is to say, the most pouplar one is the queen room. This is because most customers in Qingzhiwu are the students from Zhejiang University or courting couples. Following it are family room, balcony room and single room in sequence. Even for the same type of room, the consumers would have very different experience in different B\&Bs. Even the stiffness of the mattress can be adjusted according to the consumers' inclination---this is the appeal of B\&B. Its warmth can allow the tourists to feel at home after a long day of travelling. With B\&B becoming increasingly pluralistic, Qingzhiwu has introduced many theme hotels at present, e.g. hotel featuring the theme of cat's cote, inseparable king bird or Natsume Yuujinchou. This reflects Qingzhiwu B\&B is pursuing pluralistic and inclusive development.

\section{The first few popular room types in Qingzhiwu (unit: room)}

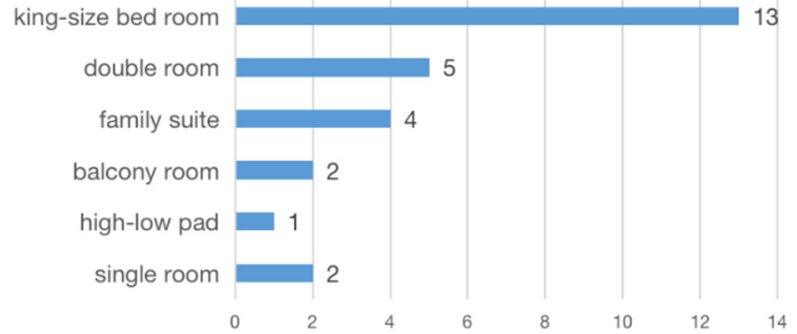

Fig 4. The most popular types of rooms in Qingzhiwu $\mathrm{B} \& \mathrm{~B}$

\subsection{The total income of Qingzhiwu B\&B}

The studies of Qingzhiwu B\&B conducted by scholars were few in the past. Graph 5 shows the total income of Qingzhiwu B\&B in Hangzhou during the period of 2015 - 
1019 based on the analysis of relevant data collected from the website of www.dianping.com. From Graph 5, we can see Qingzhiwu B\&B grew steadily in the five years from 2015 to 2019 . The annual gross income rose slowly but steadily, which indicates a bright future for this industry.

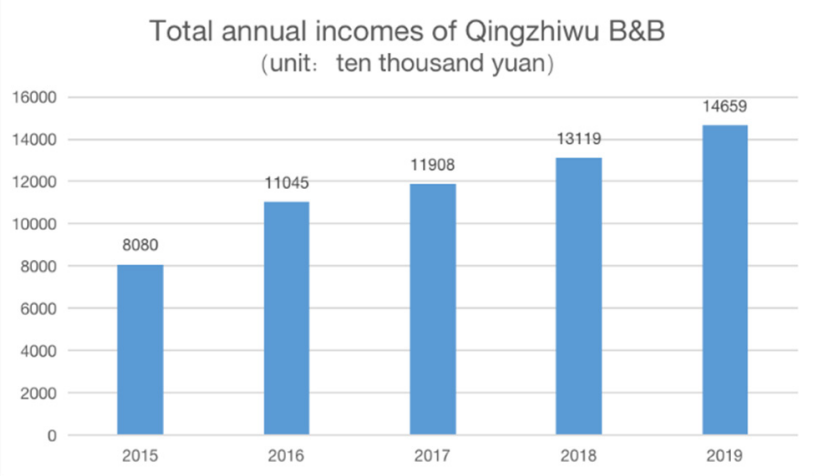

Fig 5. Total annual incomes of Qingzhiwu B\&B

\section{Suggestions for the development of Qingzhiwu B\&B}

\subsection{Currently, the most striking problems in Qingzhiwu B\&B are in the following three aspects}

(1)The absolute majority of Qingzhiwu B\&B are scattered in operation and small in scale, having little ability to ward off risks.

(2)Most of B\&Bs don't have a sound management system. The service of attendants is not standardized, which results in big difference in the experience of customers.

(3)Many B\&Bs are unable to adapt to the new demands in the era of "Internet +", and their thinking and idea on the operation and management is relatively outof-date.

\subsection{Qingzhiwu B\&B should reform in the following three aspects if it is to embrace better development by escaping from such a predicament}

(1)The management and operation of Qingzhiwu B\&B must be driven by innovation and guided by the market. They must make improvements to their service standard, and raise their ability to resist risks and promote their core competitiveness.

(2)Qingzhiwu B\&B shall enrich their room types, further their pluralism and develop characteristic B\&B service.

(3)Meanwhile, they should utilize the online platforms and brick-and-mortar shops to strengthen the publicity through modern media, tap the slow-pace life and leisure culture in Qingzhiwu represented by B\&B industry; strengthen the building of brands in E-commerce based on the slow-pace life. So tourists can find new hotspots for consumption in the publicity of products.

\section{Conclusion}

Through the way of data analysis, this paper concludes that there are some problems in the management mode, management system and development mode of Qingzhiwu residence. According to these problems, some reform suggestions are put forward from the management mode, the construction mode and the propaganda method of Qingzhiwu residence, so that the Qingzhiwu residence can get out of the predicament.

\section{References}

1. Li Yiding, Hu Jikuan and Wang Zuwen. Analysis of the Development of Chongqing Street Noodles Based on the Data from Websites like www.dianping.com--Take Nine Districts in the Main Part of Chongqing as an Example [J]. Modern Food, 2020 (07): 213-216.

2. Sun Yan, Xie Xiu and Hu Yue. Characteristics and Driving Mechanism for the Development Stage of Qingzhiwu B\&B in Hangzhou [J]. Technology and Economic Guide 2019, 27 (16): 188+187.

3. Zheng Xiaoxu and Chen Yao. Online Marketing of B\&B in the Era of "Internet+" [J]. Modern Economic Information, 2018 (22).

4. Report of Development Model Analysis and Investment Strategy Study of China's B\&B Industry During the Period of 2017-2022

5. Wang Yu. A Study of Marketing Strategies for the Rural B\&B Tourism Against the Background of "Internet+"[J]. Marketing World, 2020 (30): 9-10. 